\title{
Associations Between Household Socioeconomic Status, Car Ownership, Physical Activity, and Cardiorespiratory Fitness in South African Primary Schoolchildren Living in Marginalized Communities
}

\author{
Markus Gerber, Christin Lang, Johanna Beckmann, Jan Degen, Rosa du Randt, Stefanie Gall, \\ Kurt Z. Long, Ivan Müller, Madeleine Nienaber, Peter Steinmann, Uwe Pühse, Jürg Utzinger, \\ Siphesihle Nqweniso, and Cheryl Walter
}

\begin{abstract}
Background: Little is known whether physical activity (PA)-promoting environments are equally accessible to children with divergent socioeconomic status (SES) in low-/middle-income countries. The authors, therefore, examined whether South African children from poorer versus wealthier families living in marginalized communities differed in moderate to vigorous PA and cardiorespiratory fitness. We also tested associations between family car ownership and PA/cardiorespiratory fitness. Methods: Parents/guardians of 908 children (49\% girls, mean age $=8.3[1.4]$ y) completed a survey on household SES. PA was assessed via 7-day accelerometry, parental and child self-reports, and cardiorespiratory fitness with the 20-m shuttle run test. Results: Based on accelerometry, most children met current moderate to vigorous PA recommendations ( $\geq 60 \mathrm{~min} / \mathrm{d})$. About $73 \%$ of the children did not engage in structured physical education lessons. Whereas children of the lowest SES quintile accumulated higher levels of device-based moderate to vigorous PA, peers from the highest SES quintile engaged in more sedentary behaviors, but selfreported higher engagement in sports, dance, and moving games after school. Families' car ownership was associated with higher parent/self-reported leisure-time PA. Conclusions: A deeper understanding is needed about why wealthier children are more sedentary, but simultaneously engage in more leisure-time PA. The fact that access to structural physical education is denied to most children is critical and needs to be addressed.
\end{abstract}

Keywords: accelerometer, health inequality, household material goods, housing characteristics, wealth index

Regular physical activity (PA) is an essential element of a healthy lifestyle and is encouraged in children, adolescents, and adults. ${ }^{1}$ Systematic reviews have shown that regular PA has a positive impact on children's growth, health, and well-being. ${ }^{2,3}$ An active lifestyle has also proved to be associated with fewer cardiovascular risk markers, both in European ${ }^{4}$ and South African children. ${ }^{5}$

Recent evidence suggests that worldwide, many youngsters do not engage in sufficient PA. In a review of 298 population-based cross-sectional studies from all parts of the world, more than $80 \%$ of the 11- to 17-year-old children and adolescents did not engage in sufficient PA, with no clear pattern relative to a country's gross national product. $^{6}$ A similar picture emerged in a review of multinational studies that explicitly focused on low- and middleincome countries. ${ }^{7}$ In this review, the prevalence of insufficiently active youngsters who engage in less than 60 minutes of selfreported moderate to vigorous PA (MVPA) per day living in subSaharan African countries varied between $74 \%$ and $92 \%$. In South Africa, the Healthy Active Kids South Africa 2018 Report Card further highlighted that less than $50 \%$ of all children met recommended MVPA levels $(\geq 60 \mathrm{~min} / \mathrm{d}){ }^{8}$ Furthermore, only $30 \%$ to $60 \%$ of all school children had access to weekly school physical education, and children were spending almost 3 to 4 hours per day

Gerber, Lang, Beckmann, Degen, Gall, Müller, and Pühse are with the Department of Sport, Exercise and Health, University of Basel, Basel, Switzerland. Long, Steinmann, and Utzinger are with the University of Basel, Basel, Switzerland. du Randt, Nienaber, Nqweniso, and Walter are with the Nelson Mandela University, Port Elizabeth, Eastern Cape, South Africa. Long, Steinmann, and Utzinger are also with the Swiss Tropical and Public Health Institute, Basel, Switzerland. Gerber (markus.gerber@unibas.ch) is corresponding author. in front of a screen. Many of the studied behaviors showed a strong socioeconomic gradient and sex-based inequality so that poorer children and girls were consequently PA disadvantaged. ${ }^{9}$

As a consequence, the global action plan of the World Health Organization aims to reduce the percentage of insufficiently physically active youth and adults by $15 \%$ by $2030 .{ }^{1}$ To achieve this goal, multifaceted approaches are needed to create societies that intrinsically value regular participation in PA and where policy investments in PA have high priority in order to increase lifestyle PA. Nevertheless, this poses a particular challenge in sub-Saharan Africa where rapid social, cultural, economic, and urban development is underway. Alongside these changes, serious public health problems emerge, including an increase in sedentary lifestyles, a decline in habitual PA, and a trend toward less healthy diets, ${ }^{10}$ which are the main contributors to the increasing burden of noncommunicable diseases in sub-Saharan Africa. ${ }^{11}$

According to the social and ecological model of PA, PA behavior is influenced by environmental factors such as the availability of school physical education or the built environment (eg, neighborhood characteristics); personal factors (eg, knowledge, motivation); and social factors (eg, family, friends). ${ }^{12} \mathrm{~A}$ greater understanding of these influences on children's physical and sedentary activity is important to identify at-risk populations and to develop targeted interventions. ${ }^{13}$ Previous studies have shown that the environment can have an impact on children's PA behavior, ${ }^{14}$ and that PApromoting facilities are not always equally accessible to children with diverging socioeconomic backgrounds. ${ }^{15}$

A systematic review showed that higher socioeconomic status (SES) is associated with higher PA levels among adolescents. ${ }^{16}$ However, the same review also revealed that in $42 \%$ of the studies, 
no significant or negative relationships were found, which the authors attributed to different measures of SES, biases associated with self-reported measures of PA, as well as different types of PA assessed (eg, active transportation vs leisure time). Inconsistent findings were also observed for sedentary behavior. For instance, no clear picture emerged as to whether higher or lower SES is associated with more self-reported time spent watching television (TV). ${ }^{17}$ In summary, previous studies on the relationship between SES and PA and sedentary behavior produced mixed results. Nevertheless, research is still in an early stage, and more knowledge is needed, particularly as some scholars argued that differences in PA between children from families with lower versus families with higher SES might account for some of the differences found in health outcomes. ${ }^{18}$ For instance, previous research has shown that higher SES is associated with better health and lower all-cause mortality. ${ }^{19}$ More specifically, children from low SES families were shown to have a higher risk of being overweight, ${ }^{20}$ score higher on markers of cardiovascular risk, ${ }^{21}$ and report poorer psychological well-being 22 compared with peers from wealthier families. Since the prevention of noncommunicable diseases and mental health problems seems to become increasingly relevant to public health in African countries, ${ }^{23,24}$ more research is warranted on the relationship between SES and PA among African children, as most of the prior studies were carried out in high income countries. ${ }^{18,25}$

Sherar et al $^{18}$ further argued that the association between SES and PA may depend on the socioeconomic position of a country. "For example, in developing countries, an active lifestyle may be a necessity for those in a lower socioeconomic position, whereas in industrialized countries, technological advances have resulted in an erosion of lifestyle-embedded PA across all social strata, and a healthy active lifestyle may require more deliberate effort" (p. 546). In line with this notion, Muthuri et $\mathrm{al}^{26}$ identified 14 studies in which researchers examined the relationship between SES and PA in sub-Saharan African countries. Children with lower SES or living in rural settings had higher PA than peers with higher SES and urban children. In fact, children with lower SES engaged in more active transportation and daily duties (eg, house chores, work-related activities), while on the contrary, participation in organized sports was less common. In South African children, mixed results were reported. In line with the above findings, Lennox et $\mathrm{al}^{27}$ showed that among 15-year-old adolescents living in low socioeconomic semiurban communities in the Northwest province, participants from lower SES schools had higher activity levels than peers in higher SES schools, which was particularly attributable to more time spent for walking to school. By contrast, no significant associations between SES and objectively assessed PA were found in a study with 650 primary school children living in the Port Elizabeth region. ${ }^{5}$ McVeigh et al further found in a sample of 381 children (aged 9 y) living in the greater Johannesburg metropolitan area that higher SES was associated with higher PA levels and less time spent for sedentary activities. These findings were supported in a study with rural South African adolescents (aged 11-15 y), where higher SES was associated with more MVPA and sedentary activity, but less walking for transport. ${ }^{28}$ The latter could be explained by the fact that parents from low SES families are less likely to drive their children to school. ${ }^{29}$ This notion seems in line with an international study comparing adult black populations from 5 different sites. ${ }^{30}$ This study showed that in the United States, Seychelles, Jamaica, and Ghana, car ownership was associated with lower PA. However, although this relationship was not supported in the South African context, we are not aware of previous studies with South African children, in which family car ownership was linked to their PA behavior. Finally, with regard to physical fitness, a study with a large sample of children and adolescents from the United States (6-15 y) showed that youngsters with higher SES had better cardiorespiratory fitness (CRF) than peers from lower SES families. ${ }^{31}$ More specifically, the odds of poor CRF were 1.4 and 1.6 times higher among children with low and moderate SES, as compared with peers with high SES, respectively. Again, research with African children is scarce, and the existing studies point toward higher CRF levels among children with lower SES. 5,27

Therefore, we pursued 4 purposes with our study. First, we aimed at describing the household SES of children living in marginalized communities in peri-urban areas in the Port Elizabeth region (Eastern Cape, South Africa) based on household material goods and housing characteristics. Second, we wanted to build a wealth index to divide the population into 5 equally large groups (quintiles). Third, we examined whether SES was associated with children's PA and CRF levels. Fourth, we explored whether family car ownership was associated with lower PA/CRF levels among South African children.

\section{Methods}

\section{Participants and Procedures}

This study uses baseline data from the KaziAfya cluster randomized controlled trial, which took place in the Port Elizabeth region in February to April 2019 (more information about this study can be found in the study protocol). ${ }^{32}$ Schools were located in periurban marginalized communities from 2 areas in the Port Elizabeth region of South Africa. In the Port Elizabeth region, areas populated by black people are commonly referred to as "townships," whereas the "Northern areas" are largely made up of colored people who were forcefully relocated from the central areas of the city to the outlying northern areas. ${ }^{33,34}$ All involved schools (4 schools, 41 classes) were public schools. Public schools in South Africa are classified into 5 quintiles, with quintile one representing the poorest and quintile 5 the least poor communities. We labeled the communities as "marginalized" because all children lived in areas which have generally poor ratings with reference to national poverty tables, income levels, dependency ratios, and literacy rates. Accordingly, only quintile 3 schools (non-fee-paying schools) were involved in the present study.

School authorities were contacted first, before seeking contact with schools through the school principals. Before the start of the baseline data assessment, written informed consent was obtained from the parents/guardians of the children. Research assistants used an information sheet to explain the purpose and procedures of the study, the expected duration, potential risks and benefits, and any discomfort it may possibly entail for the children. In addition, all children provided oral assent before the start of the study.

Schools were eligible for the study if they were public schools located in marginalized communities, if facilities were available for the implementation of physical education lessons, and if they did not engage in any other research project or clinical trial. To be considered for data analyses, children had to meet the following inclusion criteria: (1) attend any of grades 1 to 4; (2) being no older than 12 years; (3) have written informed consent from their parents/ guardians; (4) not participating in other research project or clinical trial; and (5) not suffering from clinical conditions that prevent participation in PA, as determined by qualified medical personnel. 
In total, the parents/guardians of 1369 children (48\% girls and 52\% boys) provided written informed consent.

\section{Ethical Considerations}

The research ethics committee of the Nelson Mandela University (reference number: H18-HEA-HMS-006) and the Department of Education of the Eastern Cape Province provided approval for the study. In cases where a nurse diagnosed severe medical conditions and/or malnourishment (based on national guidelines), children were referred to local clinics. The study was also approved by the "Ethikkommission Nordwest- und Zentralschweiz" (EKNZ; reference number: Req-2018-00608).

\section{Measures}

Household SES was assessed via a parental survey. To estimate SES, parents/guardians answered several items about asset ownership (eg, number of bedrooms, people per household). The frequencies of the dichotomized items $(0=$ poor quality, not available; $1=$ high quality, available) were then inspected (the exact scoring and included items are provided in Supplementary Table S1 [available online]). If assets were possessed by $\geq 95 \%$ or $\leq 5 \%$ of the sample, they were excluded. The remaining items were used to carry out a principal component analysis (PCA) as described by Hjelm et al. ${ }^{35}$ The PCA was used to generate a wealth index, with higher scores reflecting higher SES. Using PCA is considered the gold standard to create a wealth index, and the validity of similar measures has been established in previous research. ${ }^{36}$ Based on the wealth index, quintiles were built (quintile $1=$ lowest/poorest; quintile $5=$ highest/wealthiest).

Habitual PA was objectively assessed via triaxial accelerometers (ActiGraph ${ }^{\circledR}$ wGT3X-BT; ActiGraph, Pensacola, FL). Evidence for the valid assessment of PA behavior via such devices has been reported previously. ${ }^{37}$ The children wore the accelerometer around the hip for 7 consecutive days, except for activities in water. The device recorded data continuously; however, a filter was set to extract only data assessed between 06.00 and 24.00 as we were only interested in daytime PA. We used a $30 \mathrm{~Hz}$ sampling rate and saved the recordings in GTX format. The data were then analyzed with the ActiLife software (version 6.13.2; ActiGraph, Pensacola, FL). At least 8 hours of accelerometer wear time was required for a day to be considered as valid. ${ }^{38}$ Nonwear time was estimated via the Troiano et $\mathrm{al}^{39}$ algorithm (and default setting). Following Clemente et al, ${ }^{40}$ children were included in the data analyses if they had valid data on $\geq 4$ weekdays and $\geq 1$ weekend day. Indices for sedentary behavior and MVPA were calculated based on child-specific cut points. ${ }^{41}$

We also asked parents/guardians to rate their children's habitual PA with a single-item from the Health-Behaviour of SchoolAged Children ${ }^{42}$ questionnaire: "Over the past 7 days (1 week), on how many days was your child physically active for a total of at least 60 minutes ( 1 hour) a day?" The options to answer the question ranged from 0 to 7 days. This question is in line with the current World Health Organization recommendation for PA among young people stating that children and youth aged 617 years should perform at least 60 minutes of MVPA per day. ${ }^{43}$

In addition, children were asked about their domain-specific PA behavior by using 5 items from the Physical Activity Questionnaire for Children. ${ }^{44}$ The Physical Activity Questionnaire for Children is a self-administered, 7-day recall instrument. In the present study, we collected information about the following domains: physical education, activity during recess, lunch, after school, and weekends. Evidence of the validity and reliability of this instrument has been reported previously. ${ }^{44}$ Answers were given separately for each domain on a 5-point Likert-type scale ranging from 1 (lowest level) to 5 (highest level).

The CRF was measured with the 20 -m shuttle run test. ${ }^{45}$ The test protocol started with a pace of $8.5 \mathrm{~km} / \mathrm{h}$. A sound signal was used to increase the speed steadily by $0.5 \mathrm{~km} / \mathrm{h}$. When children were no longer able to follow the speed of the sound signal twice in a row, the test was finished. Maximum oxygen uptake was estimated based on the speed of the last stage completed, and age. Previous research showed that the $20-\mathrm{m}$ shuttle run is a reliable and valid field test to assess CRF among children. ${ }^{46}$

A wireless body composition monitor (Tanita MC-580; Tanita Corp, Tokyo, Japan) was used to assess the body weight of the children (in light clothing, barefoot, to the nearest $0.1 \mathrm{~kg}$ ). A stadiometer was used to assess children's body height (to the nearest $0.1 \mathrm{~cm})$.

\section{Statistical Analyses}

First, descriptive statistics for each of the assessed household goods and housing characteristics were calculated. Thereafter, a series of separate PCA (with varimax rotation) were used to generate the wealth index. We excluded items and reran the PCA if betweenitem correlations were too high $(\geq .90)$ or too low $(<.10)$ or if crosstabulations did not point toward a positive relationship between the independent (quintiles) and dependent variables (household characteristics/material goods). Then, the descriptive statistics for the PA and CRF variables were calculated and the KolmogorovSmirnov test was used to examine normality. To test betweenquintile differences in PA and CRF, separate univariate analyses of covariance (ANCOVAs) were carried out. Age, sex, body mass index (BMI), and accelerometer wear time were used as covariates. To compare differences between the various wealth quintiles, contrast analyses were applied. Univariate ANCOVAs were also used to compare children from families with car access versus those without car access (with household wealth as an additional covariate). We refer to Cohen ${ }^{47}$ to interpret the effect sizes of ANCOVAs $\left(\eta^{2}<.01\right.$ : negligible; $\eta^{2} \geq .01$ : small; $\eta^{2} \geq .06$ : medium; and $\eta^{2} \geq$.138: large) and contrast analyses (Cohen $d<0.20$ : negligible; $d \geq 0.20$ : small; $d \geq 0.50$ : medium; and $d \geq 0.80$ : large). All statistical analyses were performed with SPSS 26 for Mac (IBM Corp, Armonk, NY). Statistical significance was set at $P<.05$.

\section{Results}

\section{Sample Characteristics}

Parents/guardians of 908 children (448 girls and 460 boys) completed the parental survey. Primary languages spoken at home (multiple answers possible) were Xhosa $(n=528,58.6 \%)$; Afrikaans $(n=324,36 \%)$; English $(n=159,17.6 \%)$; Zulu $(n=4$, $0.4 \%)$; Northern Sotho $(n=3,0.3 \%)$; and other languages $(n=10,1.1 \%)$. The mean age of the children was $M=8.3$ years $(S D=1.4)$, the mean height was $M=124.9 \mathrm{~cm}(S D=9.1)$, the mean weight was $M=25.7 \mathrm{~kg}(S D=7.0)$, and the mean BMI was $M=16.2 \mathrm{~m} / \mathrm{kg}^{2}(S D=2.7)$.

\section{Housing Characteristics}

As shown in Table 1, the majority of the children lived in reconstruction and development programme houses $(38.9 \%)$ or 
council houses $(24.3 \%)$. Most of the households had access to electricity (98.1\%), had access to running water $(61.3 \%)$, and had a flush toilet inside the house $(91.3 \%)$. Almost two-thirds of the households were equipped with a bathroom/shower $(58.3 \%)$. On

\section{Table 1 Overview of Housing Characteristics and Goods Possessed by Households $(N=908)$}

\begin{tabular}{|c|c|c|}
\hline Housing characteristics & $\mathbf{N}$ & $\%$ \\
\hline \multicolumn{3}{|l|}{ Type of house } \\
\hline Backyard shack/room & 97 & 12.1 \\
\hline Council house & 195 & 24.3 \\
\hline Privately built house & 94 & 11.7 \\
\hline RDP house & 313 & 38.9 \\
\hline Shack in an informal settlement & 30 & 3.7 \\
\hline Other & 75 & 8.3 \\
\hline Access to electricity in house & 891 & 98.1 \\
\hline \multicolumn{3}{|l|}{ Access to water } \\
\hline Tap inside the house & 557 & 61.3 \\
\hline Borehole with water pump & 2 & 0.2 \\
\hline Communal tap/tap shared & 25 & 2.8 \\
\hline Tap in the yard & 301 & 33.1 \\
\hline Water tank & 5 & 0.6 \\
\hline Other & 18 & 2.0 \\
\hline \multicolumn{3}{|l|}{ Type of toilet } \\
\hline Flush toilet (inside) & 828 & 91.3 \\
\hline Flush toilet (outside) & $\mathbf{0}$ & $\mathbf{0 . 0}$ \\
\hline Pit latrine & 1 & 0.1 \\
\hline Shared toilet (communal toilet) & 12 & 1.3 \\
\hline Bucket & 26 & 2.9 \\
\hline No toilet (bushes) & 3 & 0.3 \\
\hline Other & 38 & 4.2 \\
\hline \multirow[t]{2}{*}{ Bathroom } & 529 & 58.3 \\
\hline & $M$ & $S D$ \\
\hline Number of bedrooms & 2.5 & 1.2 \\
\hline Number of persons in household & 6.4 & 2.8 \\
\hline Material goods possessed by households & $N$ & $\%$ \\
\hline Car & 141 & 15.6 \\
\hline Cell phone & 731 & 80.5 \\
\hline Computer & 122 & 13.4 \\
\hline Electric oven & 449 & 49.4 \\
\hline Fan & 147 & 16.2 \\
\hline Fridge & 662 & 72.9 \\
\hline Freezer & 232 & 25.6 \\
\hline Motorbike & 9 & 1.0 \\
\hline Phone (landline) & 30 & 3.3 \\
\hline Radio & 382 & 42.1 \\
\hline Television & 734 & 80.8 \\
\hline Washing machine & 460 & 50.7 \\
\hline
\end{tabular}

Abbreviation: RDP, reconstruction and development program. Note: Variables in bold are considered for inclusion in the subsequent principal component analyses. All other variables were not considered because the percentage of missings was $\geq 2 \%$. Missings for type of house: $n=104,11.5 \%$. Missings for number of bedrooms: $n=31,3.4 \%$. Missings for number of persons in household: $n=43,4.7 \%$. average, each house had $M=2.5$ bedrooms $(S D=1.2)$, and $M=6.4$ people $(S D=2.8)$ lived in 1 household. The people per room ratio was $M=3.0(S D=1.7)$.

\section{Possession of Household Material Goods}

Table 1 provides an overview of possessed household material goods. Most households had a TV $(80.8 \%)$, a cell phone $(80.5 \%)$, and a fridge $(72.9 \%)$. About half of the households had a washing machine $(50.7 \%)$, an electric oven $(49.4 \%)$, and/or a radio $(42.1 \%)$. A total of $15.6 \%$ of the families owned a car. All other goods were possessed by less than one-third of the households, with a motorbike and landline phone being the least frequently possessed goods ( $<5 \%$ of households).

\section{Wealth Index Generation Via Principal Component Analyses}

Supplementary Table S1 (available online) shows which components were considered in the initial PCA. Three items had to be excluded because household characteristics were present in $\geq 95 \%$ of the households (access to electricity in house) or because assets were possessed by $\leq 5 \%$ (landline phone and motorbike) of the sample. Taken together, the PCA was rerun 4 times until a satisfactory solution was achieved. In the final PCA, all item correlations were $r \geq .10$, and the Kaiser-Meyer-Olkin Measure of sampling adequacy was $0.83(P<.001)$. The first factor (component 1 ) had an eigenvalue of 3.3 and explained $33.3 \%$ of variance. The factor loadings on component 1 varied between 0.40 and 0.72 . Figure 1 highlights that there was a positive association between

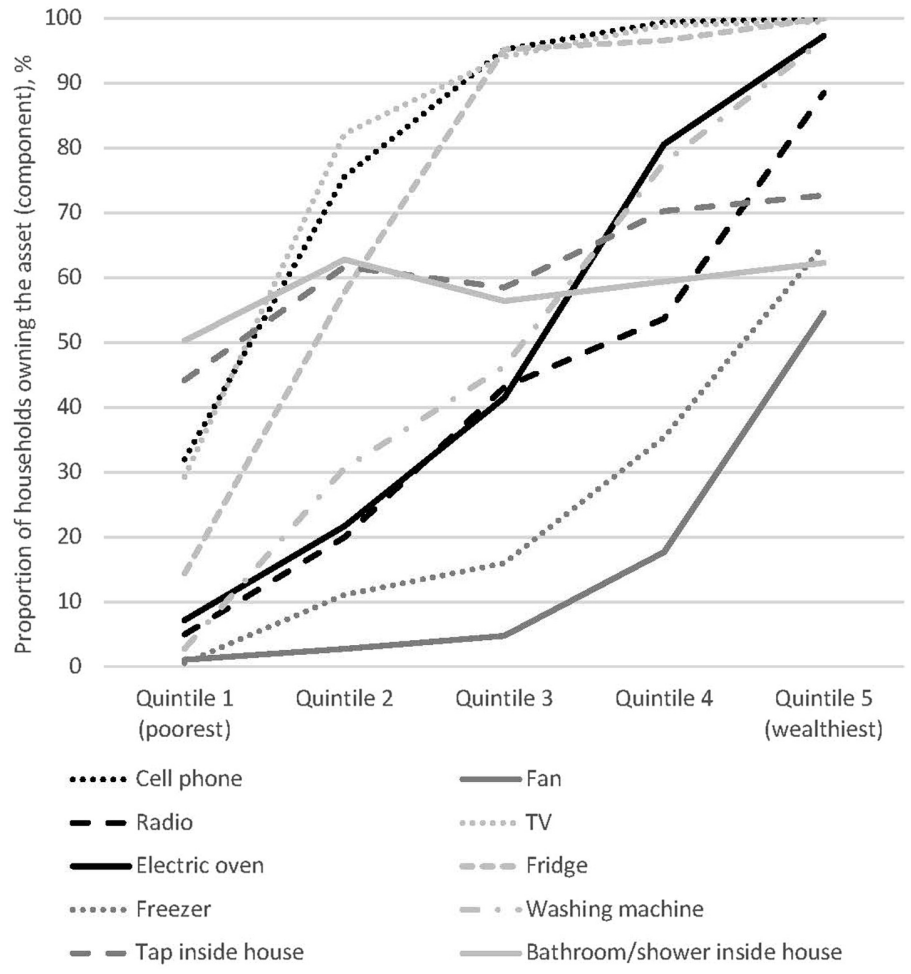

Figure 1 - Wealth index components by quintiles. 
the independent (quintiles) and dependent variables (wealth index components), with housing characteristics/material goods being more favorable/available in higher quintiles. Children from families who possessed a car had significantly higher scores on the wealth index than peers from families without a car, $F_{1,907}=77.13$, $P<.001, \eta^{2}=.079$.

\section{Descriptive Statistics}

Table 2 provides an overview of the descriptive statistics for the PA/CRF variables. These findings show that on average, children spend 611.7 minutes per day in sedentary activity and 80.6 minutes per day in MVPA. Total average accelerometer wear time was $M=1018.3$ minutes per day $(S D=47.9$; data not shown in Table 2). Most of the children included had valid PA data on 7 days $(n=777$, 93.8\%), whereas $n=41(5.0 \%)$ had valid data on 6 days and $n=10$ $(1.2 \%)$ on 5 days. On average, children engaged in sedentary activities on $60.1 \%(S D=5.7)$ of the time during which they wore the accelerometer. Average time spent for MVPA amounted to $7.9 \%(S D=2.7)$ of total accelerometer wear time. Based on accelerometer data, $76 \%$ of the children met MVPA recommendations ( $\geq 60 \mathrm{~min} / \mathrm{d}$ ). Children who met MVPA recommendations did not wear the accelerometer device more often $(M=1019.8 \mathrm{~min} / \mathrm{d}$, $S D=47.1)$ than peers who did not meet the MVPA recommendations $(M=1013.4 \mathrm{~min} / \mathrm{d}, \quad S D=50.4), \quad F_{1,827}=2.73, \quad P=\mathrm{ns}$, $\eta^{2}=.003$. The mean estimated maximum oxygen uptake was $47.5 \mathrm{~mL} / \mathrm{kg} / \mathrm{min}$. Almost 3 quarters of the children reported that they do not have $(71.4 \%)$ or hardly ever have (1.9\%) school physical education.

Kolmogorov-Smirnov tests revealed that none of the variables were normally distributed. However, no evidence was found for severe nonnormality (skewness and kurtosis values of $\geq|2|$ and $\geq \mid$ 7I, respectively). ${ }^{48}$ Accordingly, no log transformation was needed before calculating inferential statistics.

\section{Between-Quintile Differences in PA and CRF}

Table 3 provides a summary of the $M$ and $S D$, separately for the 5 quintiles. After controlling for potential confounders (age, sex, BMI, and accelerometer wear time), the ANCOVAs showed significant main effects for SES with regard to objectively assessed sedentary behavior and days of MVPA reported by parents. No significant differences were found for domain-specific activities reported by the children and CRF. Contrast analyses (Table 4) showed that children in the highest quintile accumulated more minutes per day of objectively assessed sedentary behavior than peers from the lowest quintile. By contrast, children from the lowest quintile presented with higher objectively assessed MVPA compared with peers from the highest quintile. Table 4 further shows that some contrasts between the lowest versus highest quintile became significant, although no significant main effect was identified via ANCOVA. More specifically, parents/guardians of children in the highest quintile perceived that their children accumulated sufficient MVPA $(\geq 60 \mathrm{~min} / \mathrm{d})$ on more days than parents from the poorest households. Similarly, children from the highest quintile reported higher engagement in sports, dance, or moving games on weekdays outside school hours. Inspection of the Cohen $d$ shows that the differences were small (Table 4).

\section{Car Ownership, PA, and CRF}

After controlling for potential confounders (age, sex, BMI, accelerometer wear time, and household wealth), results summarized in Table 5 point toward significant main effects of car ownership for days with $\geq 60$ minutes of MVPA reported by parents, and afterschool PA reported by the children. More specifically, parents/ guardians from car owning families reported that their children engaged in $\geq 60$ minutes of MVPA on more days than parents/ guardians from families without a car. Similarly, children from families who possessed a car self-reported higher after-school

\section{Table 2 Descriptive Statistics for the Total Sample for PA and CRF Variables}

\begin{tabular}{|c|c|c|c|c|c|c|c|}
\hline Outcome variables & $N^{a}$ & $M$ & $S D$ & Minimum & Maximum & Skewness & Kurtosis \\
\hline \multicolumn{8}{|l|}{ Objectively assessed $\mathrm{PA}^{\mathrm{b}}$} \\
\hline Sedentary activity, $\min / \mathrm{d}$ & 828 & 611.7 & 66.7 & 339.8 & 852.3 & -0.2 & 0.5 \\
\hline MVPA, $\mathrm{min} / \mathrm{d}$ & 828 & 80.6 & 27.0 & 24.5 & 197.5 & 0.7 & 0.5 \\
\hline \multicolumn{8}{|l|}{ Parental reports } \\
\hline Days with $\geq 60$-min MVPA & 811 & 5.4 & 2.1 & 0 & 7 & -1.0 & -1.0 \\
\hline \multicolumn{8}{|l|}{ Child reports } \\
\hline Physical education $^{c}$ & 891 & 1.8 & 1.4 & 1 & 5 & 1.3 & 0.1 \\
\hline Recess $^{\mathrm{d}}$ & 890 & 3.5 & 1.5 & 1 & 5 & -0.5 & -1.2 \\
\hline Lunch $^{\mathrm{d}}$ & 886 & 3.4 & 1.5 & 1 & 5 & -0.4 & -1.3 \\
\hline After school ${ }^{\mathrm{e}}$ & 891 & 2.2 & 1.5 & 0 & 4 & -0.2 & -1.4 \\
\hline Weekend ${ }^{\mathrm{f}}$ & 889 & 2.6 & 1.4 & 0 & 4 & -0.4 & -1.1 \\
\hline \multicolumn{8}{|l|}{ CRF } \\
\hline Laps completed in $20-\mathrm{m}$ shuttle run & 891 & 22.0 & 13.7 & 2 & 113 & 1.9 & 5.5 \\
\hline Estimated $\mathrm{VO}_{2} \mathrm{max}, \mathrm{mL} / \mathrm{kg} / \mathrm{min}$ & 891 & 47.5 & 3.9 & 35.9 & 65.0 & 0.5 & 1.3 \\
\hline
\end{tabular}

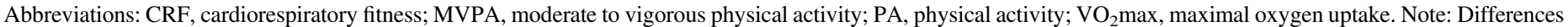
in number of participants are due to different number of missing values in the various outcome variables.

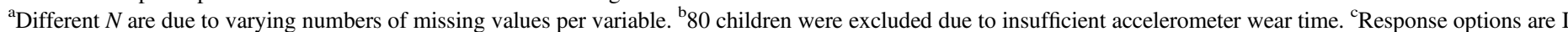

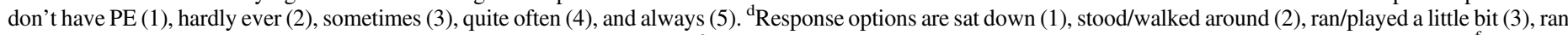

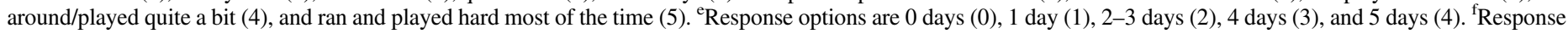
options are none (0), 1 time (1), 2-3 times (2), 4-5 times (3), and $\geq 6$ times (4). 


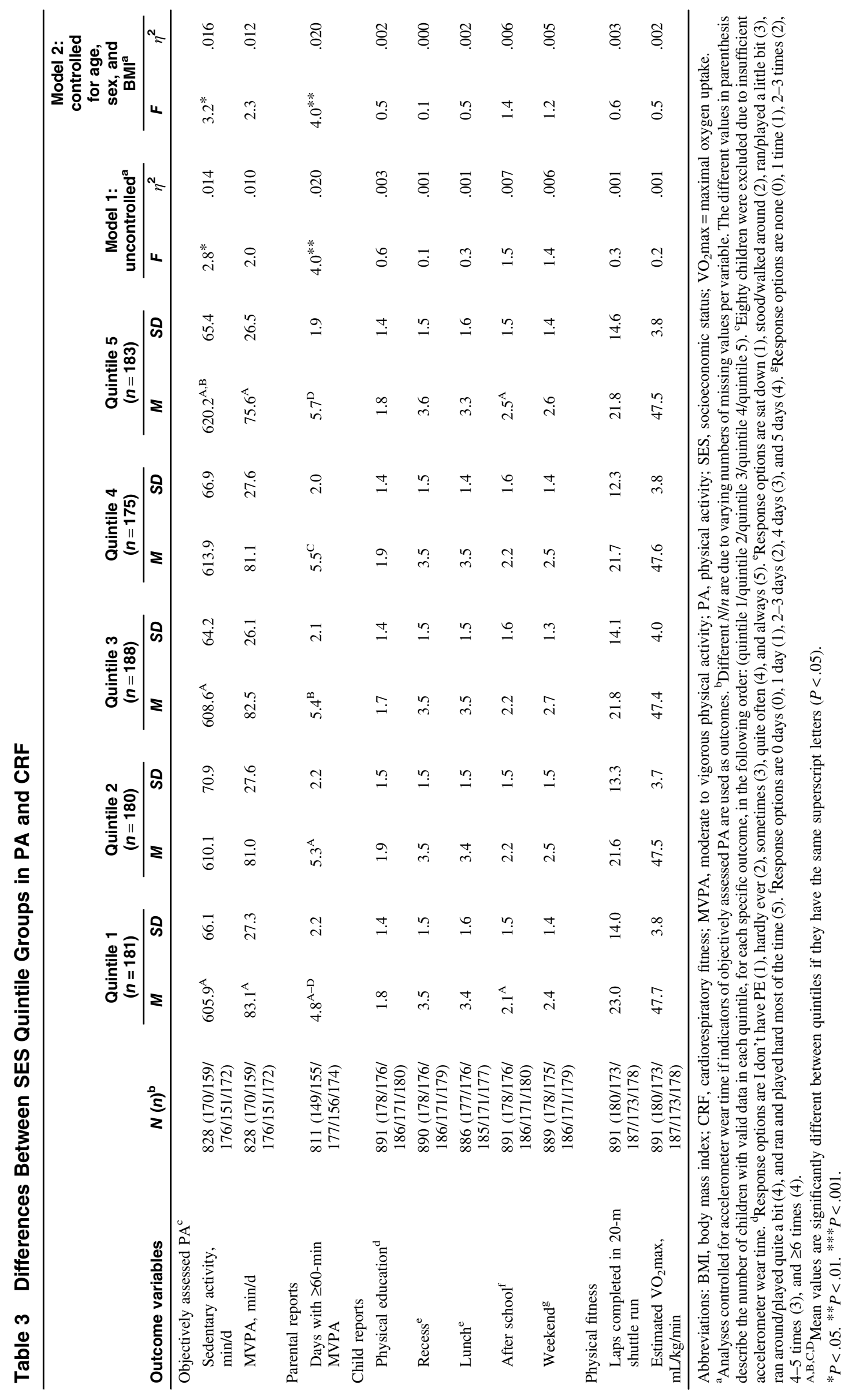




\begin{tabular}{|c|c|c|c|c|c|c|c|}
\hline \multirow[b]{2}{*}{ Outcome variables } & \multirow[b]{2}{*}{$n^{b}$} & \multicolumn{3}{|c|}{$\begin{array}{l}\text { Contrast between quintiles } 1 \\
\text { and } 5^{\mathrm{a}}\end{array}$} & \multicolumn{3}{|c|}{$\begin{array}{c}\text { Contrast between children } \\
\text { from families with vs } \\
\text { without a car }\end{array}$} \\
\hline & & $t$ & $\boldsymbol{P}$ & $d$ & $t$ & $\boldsymbol{P}$ & $d$ \\
\hline \multicolumn{8}{|l|}{ Objectively assessed $\mathrm{PA}^{\mathrm{c}}$} \\
\hline Sedentary activity, $\mathrm{min} / \mathrm{d}$ & $170 / 172$ & 1.99 & .047 & 0.22 & .4 & 672 & 0.04 \\
\hline MVPA, $\min / \mathrm{d}$ & $170 / 172$ & -2.59 & .010 & -0.28 & -.52 & .603 & -0.05 \\
\hline \multicolumn{8}{|l|}{ Parental reports } \\
\hline Days with $\geq 60$-min MVPA & $140 / 163$ & 3.87 & $<.001$ & 0.44 & 3.1 & .002 & 0.29 \\
\hline \multicolumn{8}{|l|}{ Child reports } \\
\hline Physical education $^{\mathrm{d}}$ & $167 / 169$ & .35 & .725 & 0.04 & 1.9 & .060 & 0.19 \\
\hline Recess $^{\mathrm{e}}$ & $167 / 169$ & .65 & .514 & 0.07 & 1.8 & .071 & 0.17 \\
\hline Lunch $^{\mathrm{e}}$ & $167 / 167$ & -.35 & .724 & -0.04 & .0 & .975 & 0.00 \\
\hline After school $^{\mathrm{f}}$ & $167 / 169$ & 2.17 & .030 & 0.23 & 3.1 & .002 & 0.29 \\
\hline Weekend $^{\mathrm{g}}$ & $167 / 169$ & 1.38 & .168 & 0.16 & 1.3 & .213 & 0.11 \\
\hline \multicolumn{8}{|l|}{ Physical fitness } \\
\hline Laps completed in $20-\mathrm{m}$ shuttle run & $169 / 169$ & -.77 & .44 & -0.08 & -1.1 & .255 & -0.10 \\
\hline Estimated $\mathrm{VO}_{2} \max$ & $169 / 169$ & -.27 & .496 & -0.07 & -1.3 & .189 & -0.12 \\
\hline
\end{tabular}

Abbreviations: CRF, cardiorespiratory fitness; MVPA, moderate to vigorous physical activity; PA, physical activity; $\mathrm{VO}_{2}$ max, maximal oxygen uptake. Note: Cohen $d$ should be interpreted as follows: $d<0.2$ (negligible effect), $d \geq 0.2$ (small effect), $d \geq 0.5$ (medium effect), and $d \geq 0.80$ (large effect).

${ }^{\mathrm{a}}$ Quintile 1: $n=181$. Quintile 5: $n=183$. ${ }^{\mathrm{b}}$ Different $n$ are due to varying numbers of missing values per variable. First value represents number of children with valid data in quintile 1 , second value describes number of children with valid data in quintile $5 .{ }^{c}$ Eighty children were excluded due to insufficient accelerometer wear time. ${ }^{\mathrm{d}}$ Response options are I don't have PE (1), hardly ever (2), sometimes (3), quite often (4), and always (5). ${ }^{\mathrm{e}}$ Response options are sat down (1), stood/walked around (2), ran/played a little bit (3), ran around/played quite a bit (4), and ran and played hard most of the time (5). ${ }^{\mathrm{f}}$ Response options are 0 days (0), 1 day (1), $2-3$ days (2), 4 days (3), and 5 days (4). ${ }^{g}$ Response options are none (0), 1 time (1), 2-3 times (2), 4-5 times (3), and $\geq 6$ times (4).

Table 5 Differences in PA and CRF Between Children From Families With Versus Without a Car

\begin{tabular}{|c|c|c|c|c|c|c|c|c|c|}
\hline \multirow[b]{2}{*}{ Outcome variables } & \multirow[b]{2}{*}{$N(n)^{c}$} & \multicolumn{2}{|c|}{$\begin{array}{c}\text { No car } \\
(n=766)\end{array}$} & \multicolumn{2}{|c|}{ Car $(n=142)$} & \multicolumn{2}{|c|}{$\begin{array}{c}\text { Model 1: } \\
\text { uncontrolled }^{\mathrm{a}}\end{array}$} & \multicolumn{2}{|c|}{$\begin{array}{l}\text { Model 2: } \\
\text { controlled } \\
\text { for age, sex, } \\
\text { BMI, and } \\
\text { wealth }^{\mathbf{b}}\end{array}$} \\
\hline & & $M$ & $S D$ & $M$ & $S D$ & $\boldsymbol{F}$ & $\eta^{2}$ & $\boldsymbol{F}$ & $\eta^{2}$ \\
\hline \multicolumn{10}{|l|}{ Objectively assessed $\mathrm{PA}^{\mathrm{d}}$} \\
\hline Sedentary activity, $\min / \mathrm{d}$ & $828(698 / 130)$ & 611.3 & 66.6 & 614.0 & 67.3 & 0.2 & .000 & 0.0 & .000 \\
\hline MVPA, $\mathrm{min} / \mathrm{d}$ & $828(698 / 130)$ & 80.9 & 27.0 & 79.5 & 27.5 & 0.3 & .000 & 0.0 & .000 \\
\hline \multicolumn{10}{|l|}{ Parental reports } \\
\hline Days with $\geq 60$-min MVPA & $811(679 / 132)$ & 5.3 & 2.2 & 5.9 & 1.7 & $9.5^{* *}$ & .012 & $4.4^{*}$ & .006 \\
\hline \multicolumn{10}{|l|}{ Child reports } \\
\hline Physical education $^{\mathrm{e}}$ & $891(750 / 141)$ & 1.8 & 1.4 & 2.1 & 1.5 & $4.1^{*}$ & .005 & 2.9 & .003 \\
\hline Recess $^{\mathrm{f}}$ & $890(749 / 141)$ & 3.5 & 1.5 & 3.7 & 1.5 & 3.3 & .004 & 1.3 & .001 \\
\hline Lunch $^{\mathrm{f}}$ & $886(745 / 141)$ & 3.4 & 1.5 & 3.4 & 1.5 & 0.0 & .000 & 0.1 & .000 \\
\hline After school $^{\mathrm{g}}$ & $891(750 / 141)$ & 2.2 & 1.5 & 2.6 & 1.5 & $9.7^{* *}$ & .011 & $6.0^{*}$ & .007 \\
\hline Weekend $^{\mathrm{a}}$ & $889(748 / 141)$ & 2.5 & 1.4 & 2.7 & 1.4 & 1.5 & .002 & 0.3 & .000 \\
\hline \multicolumn{10}{|l|}{ Physical fitness } \\
\hline Laps completed in $20-\mathrm{m}$ shuttle run & $891(750 / 141)$ & 22.2 & 13.8 & 20.8 & 13.1 & 1.2 & .001 & 0.5 & .001 \\
\hline Estimated $\mathrm{VO}_{2} \mathrm{max}, \mathrm{mL} / \mathrm{kg} / \mathrm{min}$ & $891(750 / 141)$ & 47.6 & 3.8 & 47.1 & 3.7 & 1.7 & .002 & 0.7 & .001 \\
\hline
\end{tabular}

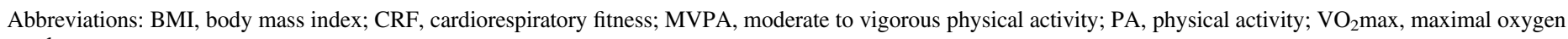
uptake.

${ }^{\mathrm{a}}$ Response options are none (0), 1 time (1), 2-3 times (2), 4-5 times (3), and $\geq 6$ times (4). ${ }^{\mathrm{b}}$ Analyses controlled for accelerometer wear time if indicators of objectively assessed PA are used as outcomes. ${ }^{c}$ Different $N / n$ are due to varying numbers of missing values per variable. The different values in parenthesis describe the number of children with valid data in each group, for each specific outcome, in the following order: (no car/car). ${ }^{\mathrm{d}}$ Eighty children were excluded due to insufficient accelerometer wear time. ${ }^{\mathrm{e}}$ Response options are I don't have PE (1), hardly ever (2), sometimes (3), quite often (4), and always (5). ${ }^{\mathrm{f}}$ Response options are sat down (1), stood/walked around (2), ran/played a little bit (3), ran around/played quite a bit (4), and ran and played hard most of the time (5). ${ }^{\mathrm{g}}$ Response options are 0 days (0), 1 day (1), 2-3 days (2), 4 days (3), and 5 days (4).

${ }^{*} P<.05 ;{ }^{* *} P<.01 ;{ }^{* * *} P<.001$ 
engagement in sports, dance, or moving games. The significant main effect for physical education disappeared after controlling for potential confounders. Cohen $d$ shows that the identified differences were small (Table 4). No significant differences were observed for objectively assessed MVPA and sedentary behavior and $\mathrm{CRF}$.

\section{Discussion}

The key findings of the present study are that according to international guidelines ( $\geq 60 \mathrm{~min} \mathrm{MVPA} / \mathrm{d})$, most children of the present population engaged in sufficient PA, and that their CRF levels were good. Nevertheless, only a quarter of the children reported that they had the opportunity to take part in structured physical education lessons at school on a regular basis. Whereas children of the lowest quintile accumulated higher levels of objectively assessed MVPA than children from the highest quintile, the latter engaged in more sedentary behaviors. On the other hand, children from the highest quintile reported that they engaged in sports, dance, and moving games more often after school than children from the lowest quintile. We also observed that parents/ guardians of children in the highest quintile reported that their children accumulated sufficient PA on more days than parents from the lowest quintiles. Similarly, children from car-owning families presented with higher PA levels during their leisure time than peers from families without car access.

In the present study, 4 purposes were pursued. The first purpose was to describe the household SES of children in marginalized communities in peri-urban areas. The present study shows that most households possessed a TV, a telephone, and a fridge, which is in line with a previous study with South African children. ${ }^{49}$ Moreover, the average number of assets possessed, and positive housing characteristics was $M=5.4(S D=2.6$; data not shown), which highlights that there was considerable variation in household SES, although all children from this sample lived in marginalized areas that are characterized by relatively poor ratings with reference to national poverty tables and income levels.

The second purpose of this study was to examine whether the assessed household assets and housing characteristics facilitate the building a wealth index in order to divide the population into 5 equally large groups (quintiles). Using PCA to generate a wealth index is considered the gold standard procedure, which is also applied by the World Bank and the United Nations to monitor socioeconomic development in low- and middle-income countries. ${ }^{30} \mathrm{We}$ are not aware of previous studies in which this approach has been used to assess the relationship between household SES and PA in South African children. For this reason, a central methodological weakness of prior research was addressed in the present study. Since our findings show that the assessed housing characteristics/material goods were suitable to build a family wealth index, we also strongly recommend this approach for future investigations.

The third purpose of our study was to examine whether SES was associated with children's PA and CRF levels. Previous studies with young people have shown that PA and CRF differ between children and adolescents with divergent socioeconomic backgrounds. ${ }^{16,25,26,31}$ This supports the notion that families have an important impact on children's PA behavior by creating access to facilities or encouraging them to participate in organized sport activities. ${ }^{50}$ It has also been argued that the built environment may have a particularly strong impact on children's PA behavior in low SES families, ${ }^{51}$ as it is associated with access to parks, street connectivity, levels of crime, and the aesthetic quality of the neighbourhood. ${ }^{52}$ However, different relationships were found in high- and low-income countries. Whereas in high-income countries, higher SES is typically associated with higher PA/ CRF levels, ${ }^{16,25}$ the associations seem more complex in subSaharan African countries. More specifically, Muthuri et $\mathrm{al}^{26}$ found in their review that whereas children with lower SES had higher PA than higher SES peers (particularly because they engaged in more active transportation, more house chores, and more work-related activities), the latter participated more frequently in organized sports and formal activities. Moreover, as in our study, no significant differences between children with higher versus lower SES were found in CRF in another study carried out in a middle-income country (Colombia). ${ }^{53}$ Our findings corroborate these findings. Thus, whereas children from the lowest wealth-quintile accumulate higher overall objectively assessed MVPA than their counterparts from the highest quintile, they seem to engage less frequently in leisure-time PA (as reported by themselves as well as their parents). The effect sizes revealed relatively small differences. However, several factors might have made it more difficult to detect larger associations between SES and PA/CRF. First, the sample presented with relatively high PA/CRF levels (see below for more details), which entails the risk of a ceiling effect. Second, we did not use a population-based sample. Rather, children were recruited from marginalized communities living in peri-urban settings. Thus, although we were able to generate wealth quintiles based on assessed housing characteristics/material goods, the variation in household SES may have been lower in our sample than it would be in a more general population. Third, our sample was relatively young, whereas most previous studies focused on older children or adolescents. This is important because social influences might become more relevant when the natural urge to be physically active decreases. ${ }^{54}$

The fourth purpose of this study was to explore whether family car ownership was associated with lower PA/CRF levels among South African children. The fact that in our study family car ownership was positively associated with children's PA levels was an interesting observation. In high-income countries, it has been observed that although PA is a basic need for children, cultural changes have "engineered" spontaneous PA out of the daily lives of many children and adolescents. ${ }^{55}$ However, the relationship between cultural changes and PA behavior is complex. Thus, while technological advances related to transport, labor, housekeeping, meal preparation, and leisure pursuits may have a negative impact on PA behavior, other socioeconomic developments may lead to more leisure time, and thus may have a positive effect on PA. ${ }^{30}$ The findings of our study are at odds with data from 5 pooled cohort studies carried out in the United Kingdom, Australia, and Brazil, ${ }^{56}$ in which children living in households with car access were more sedentary and less active than their peers without. The findings of our study shed new light on this topic because so far, very few studies have examined the relationship between car access and PA among school-aged children living in low-income contexts. Although not directly assessed, it is possible that in our study setting, car access facilitated access to PA-friendly environments for children. Given the lack of previous research in low- and middle-income countries, additional studies are needed to examine whether or not our results can be replicated, and to better understand potential underlying mechanisms.

Moreover, whether or not South African children are sufficiently or insufficiently active remains a matter of debate. For instance, in a study with rural South African children aged 7-15 years, in which 
PA was assessed via accelerometry, Craig et $\mathrm{al}^{57}$ found that although total PA was high, only a very low percentage was spent in MVPA. By contrast, other studies have reported relatively high PA levels among South African schoolchildren, with more than $80 \%$ meeting international MVPA recommendations $(\geq 60 \mathrm{~min} /$ d). ${ }^{58-60}$ Given that PA is one of the most relevant modifiable risk factors for chronic diseases, the fact that in our study most children (76\%) accumulated $\geq 60$ minutes of (objectively assessed) MVPA per day is a positive finding. Abernathy et $\mathrm{al}^{61}$ claimed that it might be possible to mitigate some of the health risks associated with poverty, if societies successfully implement policies that target the promotion of PA among the poorest social strata. Moreover, based on a systematic review of the literature, Ruiz et $\mathrm{al}^{62}$ claimed that to avoid cardiovascular disease risk, boys should have maximum oxygen uptake scores higher than $41.8 \mathrm{~mL} / \mathrm{kg} / \mathrm{min}$ and girls higher than $34.6 \mathrm{~mL} / \mathrm{kg} / \mathrm{min}$. In the present study, on average, both boys $(M=47.8, S D=4.1)$ and girls $(M=47.3, S D=3.5)$ clearly exceeded these sex-specific cut offs. More specifically, $94 \%$ of the boys and $100 \%$ of the girls were above these cut off values. This is encouraging as child CRF proved to predict cardiovascular risk profiles in adulthood, including metabolic syndrome and arterial stiffness. ${ }^{63}$

Evidence further suggests that the nature and quality of PA behavior of children in low-income settings might differ from children living in high-income settings. For instance, studies have highlighted that in low-income urban settings, only a small fraction of PA stems from organized, structured, and teacher-led activities. ${ }^{64}$ One reason might be that, in these settings, children have limited access to extracurricular PA such as organized team activities, coaching and structured lessons. As a consequence, most of the observed PA may result from informal and unstructured PA including running around, playing with tires, or climbing fixed equipment. ${ }^{65}$ Our study supports this notion. Thus, only a minority of our study population had the chance to take part in structured physical education lessons at school. This situation can be attributed to the fact that in 1994 physical education in schools lost its stand-alone status and was marginalized in the South African national curriculum. ${ }^{66}$ More specifically, physical education was combined with other subjects in the "Life Orientation" learning area. Accordingly, the promotion of PA programs in schools is no longer mandatory, and as our data show, only few teachers seem to use the Life Orientation subject to provide structured physical education classes. This is critical, because as Pienaar et $\mathrm{al}^{67}$ and Pienaar and Kemp ${ }^{68}$ demonstrated that many primary schoolchildren in South Africa have limited motor proficiency (particularly girls). Other researchers found that in South African preschool children, motor skill proficiency is higher among children living in rural compared with urban low-income settings. ${ }^{69}$ More specifically, in a sample of more than 800 children, $23 \%$ had insufficient object control skills and more than $50 \%$ presented with below average total scores. In line with these findings, Hills et al ${ }^{55}$ argued that developing fundamental movement skills via structured school physical education is essential for the adoption of regular PA. Without such opportunities, a physically active lifestyle might be jeopardized at an early age, which may entail negative consequences for children's growth and development. Nevertheless, Uys et $\mathrm{al}^{70}$ have previously highlighted that the delivery and quality of implementation of physical education is insufficient at many South African schools. Time constraints, teachers' workloads, and reluctance of staff members to become involved in noncompulsory activities were identified as key factors for the insufficient implementation. Unfortunately, in our study, we did not explicitly distinguish between participation in structured/organized versus informal PA outside school hours. This distinction deserves more attention in the future because engagement in PA in structured/ organized settings may have a particularly great potential to promote children's fundamental movement skills. ${ }^{71}$

The strengths of our study were that we used housing characteristics/household material goods to build a wealth index, which provides better proxies of long-term SES than income or expenditure, which are sometimes difficult to assess and depend more on short-term economic change. ${ }^{35}$ Another advantage was that we combined different approaches to assess the PA behavior of children (accelerometry, parental reports, self-ratings, and fitness tests). This is important because the correlations between these measures were relatively low in the present study (all $r \mathrm{~s}<.22$, data not shown), which suggests that these measures are relatively independent and thus may shed light on children's PA behavior from different perspectives. We also examined whether children who meet MVPA recommendations versus do not meet MVPA recommendations differ with regard to accelerometer wear time in order to rule out that differences in MVPA merely reflect differences in accelerometer wear time and not differences in actual PA behavior. The use of accelerometer data also allowed us to assess objective information about sedentary behavior. In the contemporary epidemiological literature, sedentary behavior and MVPA are described as 2 different behaviors. ${ }^{72}$ In other words, sedentariness (which includes behaviors such as television viewing or traveling by motorized transport) is not a synonym for the absence of MVPA, and may thus be considered as an independent health risk. ${ }^{73}$ Finally, ANCOVAs were controlled for potential confounders such as sex, age, BMI, and accelerometer wear time. Limitations of our study are that the analyses are based on cross-sectional data, which precludes conclusions about cause and effect. Moreover, although 1369 parents/guardians provided informed consent, only 908 parents/guardians $(66.3 \%)$ provided information about housing characteristics/household material goods, which might have introduced a bias. We also had to exclude a substantial number of children $(n=80,8.8 \%)$ due to insufficient accelerometer wear time, which lead to a further reduction of the sample size in some variables. We also acknowledge that beyond SES, many other family influences (eg, number of siblings, number of family visits to parks, family sport participation, parental screen time, parental restriction on playing outside) may influence children's PA behavior. We did not assess specific information about the time children spent watching TV or using their cell phones, although these sedentary behaviors are highly prevalent among children and adolescents, ${ }^{74}$ and proved to be associated with their PA behavior in prior research. ${ }^{75-77}$ More attention should be paid to these factors in future studies. Finally, we did not adjust our analyses for the compositional nature of the data, also such approaches have been advocated in recently published research. ${ }^{78}$

\section{Conclusions}

This is the first study that used a PCA approach to examine the association between SES and PA/CRF in South African primary schoolchildren. Our findings add to the growing body of literature showing that SES and family factors are associated with children's PA behavior. In our sample, most children engaged in sufficient PA $(76 \%)$ and presented with adequate CRF levels ( $\geq 94 \%)$. Nevertheless, few children had the opportunity to participate in structured school physical education lessons, which might have negative consequences for their long-term motor development. 
A stratification by wealth index quintiles showed that children from the highest quintile engaged in more sedentary behavior, but also had more opportunities to engage in after-school PA. Children from the lowest quintile, in turn, accumulated the highest level of objectively assessed MVPA, whereas children from families with car access self-reported a higher engagement in leisure-time PA. Further research is needed not only to replicate the present data, but also to gain a deeper understanding about the mechanisms underlying these relationships. While much more work is needed before any concrete recommendations can be made regarding the promotion of specific types of PA in different socioeconomic strata, our findings set the stage for novel research directions in this area. More specifically, we recommend that research go beyond measuring total amounts of PA, and recommend collecting more (qualitative) information about the specific contexts and circumstances under which children's PA takes place. Finally, the present study highlights that in South Africa, many children living in marginalized communities are denied access to structural physical education lessons at school. Since physical education is part of the official curriculum, and since school is the place where all children-regardless of their socioeconomic background-have the opportunity to engage in quality physical education on a regular basis, this situation is unsatisfactory and needs to be addressed as soon as possible.

\section{Acknowledgments}

The authors thank Larissa Adams, Nandi Joubert, Danielle Smith and Zaahira Ismail for their contribution to data collection. The authors also thank all involved Master's students from the University of Basel, Switzerland (Lisa von Polanen, Nora Degonda, Ilir Freitag, and Selma Catakovic) and the University of Vienna, Austria (Christina Polak and Dominique Greger) for their support in the data collection and processing. Finally, the authors thank the school authorities, school principals, teachers, students, and parents/legal guardians for their willingness to support our study. The study is funded by Foundation Botnar (Basel, Switzerland; grant number: 6071). The registration number is https://doi.org/10.1186/ ISRCTN29534081.

\section{References}

1. WHO. Global Action Plan on Physical Activity: More Active People for a Healthier World 2018-2030. Geneva, Switzerland: World Health Organization; 2018.

2. Donnelly JE, Hillman CH, Castelli D, et al. Physical activity, fitness, cognitive function, and academic achievement in children: a systematic review. Med Sci Sports Exerc. 2016;48(6):1197-1222. doi:10. 1249/MSS.0000000000000901

3. Eime RM, Young JA, Harvey JT, et al. A systematic review of the psychobiological and social benefits of participation in sport for children and adolescents: informing development of a conceptual model of health through sport. Int J Behav Nutr Phys Act. 2013;10(1):98-118. PubMed ID: 23945179 doi:10.1186/14795868-10-98

4. Ekelund U, Anderssen SA, Froberg K, et al. Independent associations of physical activity and cardiorespiratory fitness with metabolic risk factors in children: the European Youth Heart Study. Diabetologia. 2007;50(9):1832-1840. PubMed ID: 17641870 doi:10.1007/s00125007-0762-5

5. Müller I, Walter C, du Randt R, et al. Association between physical activity, cardiorespiratory fitness and clustered cardiovascular risk in
South African children from disadvantaged communities: results from a cross-sectional study. BMJ Open Sport Exerc Med. 2020; 6(1):e000823. doi:10.1136/bmjsem-2020-000823

6. Guthold R, Stevens GA, Riley LM, et al. Global trends in insufficient physical activity among adolescents: a pooled analysis of 298 population-based surveys with 1.6 million participants. Lancet Child Adolesc Health. 2020;4(1):23-35. PubMed ID: 31761562 doi:10. 1016/S2352-4642(19)30323-2

7. Darfour-Oduro SA, Buchner DM, Andrade JE, et al. A comparative study of fruit and vegetable consumption and physical activity among adolescents in 49 low-and-middle-income countries. Sci Rep. 2018;8(1):1623. PubMed ID: 29374197 doi:10.1038/s41598-01819956-0

8. Draper CE, Tomaz SA, Harbron J, et al. Results from the healthy active kids South Africa 2018 report card. S Afr J Child Health. 2019;13(3):130-36. doi:10.7196/SAJCH.2019.v13i3.1640

9. Draper CE, Basset S, de Villiers A, et al. Results from South Africa's 2014 report card on physical activity for children and youth. $J$ Phys Act Health. 2014;11:S98-S104. PubMed ID: 25426923 doi:10.1123/ jpah.2014-0185

10. Kidokoro T, Fuku N, Yanagiya T, et al. Physical activity and sedentary behaviour patterns among Kenyan and Japanese children: a comprehensive cross-country comparison. Int J Environ Res Public Health. 2020;17(12):4254. doi:10.3390/ijerph17124254

11. Popkin BM, Gordon-Larsen P. The nutrition transition: worldwide obesity dynamics and their determinants. Int J Obes Relat Metab Disord. 2004;28:S2-S9. doi:10.1038/sj.ijo.0802804

12. Sallis JF, Glanz K. The role of built environments in physical activity, eating, and obesity in childhood. Future Child. 2006;16(1):89-108. PubMed ID: 16532660 doi:10.1353/foc.2006.0009

13. Spinks A, Macpherson A, McClure R. Determinants of sufficient daily physical activity in Australian primary school children. $J$ Paediatr Child Health. 2006;42(11):674-679. PubMed ID: 17044893 doi:10.1111/j.1440-1754.2006.00950.x

14. Ding D, Sallis JF, Kerr J, et al. Neighborhood environment and physical activity among youth: a review. Am J Prev Med. 2011;41(4):442-455. PubMed ID: 21961474 doi:10.1016/j.amepre. 2011.06.036

15. Miyake KK, Maroko AR, Grady KL, et al. Not just a walk in the park: methodological improvements for determining environmental justice implications of park access in New York city for the promotion of physical activity. Cities and Environment. 2010;3(1):1-17. doi:10. 15365/cate. 3182010

16. Stralsberg R, Pedersen AV. Effects of socioeconomic status on the physical activity in adolescents: a systematic review of the evidence. Scand J Med Sci Sports. 2010;20:368-383. doi:10.1111/j.1600-0838. 2009.01047.x

17. Coombs N, Shelton N, Rowlands AV, et al. Children's and adolescents' sedentary behaviour in relation to socioeconomic position. $J$ Epidemiol Community Health. 2013;67(10):868-874. PubMed ID: 23851152 doi:10.1136/jech-2013-202609

18. Sherar LB, Griffin TP, Ekelund U, et al. Association between maternal education and objectively measured physical activity and sedentary time in adolescents. J Epidemiol Community Health. 2016;70(6):541-548. PubMed ID: 26802168 doi:10.1136/jech2015-205763

19. Pollitt RA, Kaufman JS, Rose KM, et al. Early-life and adult socioeconomic status and inflammatory risk markers in adulthood. Eur J Epidemiol. 2007;22(1):55-66. PubMed ID: 17225957 doi:10. 1007/s10654-006-9082-1

20. Lioret S, Maire B, Volatier JL, et al. Child overweight in France and its relationship with physical activity, sedentary behaviour and 
socioeconomic status. Eur J Clin Nutr. 2007;61(4):509-516. PubMed ID: 16988644 doi:10.1038/sj.ejcn.1602538

21. Kristensen PL, Wedderkopp N, Møller NC, et al. Tracking and prevalence of cardiovascular disease risk factors across socio-economic classes: a longitudinal substudy of the European Youth Heart study. BMC Public Health. 2006;6(1):20. PubMed ID: 16441892 doi:10.1186/1471-2458-6-20

22. Huurre T, Aro H, Rahkonen O. Well-being and health behaviour by parental socioeconomic status: a follow-up study of adolescents aged 16 until age 32 years. Soc Psychiatry Psychiatr Epidemiol. 2003; 38(5):249-255. PubMed ID: 12719840 doi:10.1007/s00127-0030630-7

23. Bigna JJ, Noubiap JJ. The rising burden of non-communicable diseases in sub-Saharan Africa. Lancet Glob Health. 2019;7(10): e1295-e96. PubMed ID: 31537347 doi:10.1016/S2214-109X(19) 30370-5

24. Sankoh O, Sevalie S, Weston M. Mental health in Africa. Lancet Glob Health. 2018;6(9):e954-e55. PubMed ID: 30103990 doi:10.1016/ S2214-109X(18)30303-6

25. Brodersen NH, Steptoe A, Boniface DR, et al. Trends in physical activity and sedentary behaviour in adolescence: ethnic and socioeconomic differences. Br J Sports Med. 2007;41(3):140-144. PubMed ID: 17178773 doi:10.1136/bjsm.2006.031138

26. Muthuri SK, Wachira LJ, Leblanc AG, et al. Temporal trends and correlates of physical activity, sedentary behavior, and physical fitness among school-aged children in Sub-Saharan Africa: a systematic review. Int J Environ Res Public Health. 2014;11(3):3327-3359. PubMed ID: 24658411 doi:10.3390/ijerph110303327

27. Lennox A, Pienaar AE, Wilders C. Physical fitness and the physical activity status of 15-year-old adolescents in a semi-urban community. S Afr J Res Sport Phys Educ Recreation. 2008;30:59-73.

28. Micklesfield LK, Pedro TM, Twine R, et al. Physical activity patterns and determinants in rural South African adolescents. J Sci Med Sport. 2012;15:S251. doi:10.1016/j.jsams.2012.11.610

29. Shokoohi R, Hanif NR, Dali M. Influence of the socio-economic factors on children's school travel. Procedia Soc Behav Sci. 2012; 50:135-147. doi:10.1016/j.sbspro.2012.08.022

30. Shoham DA, Dugas LR, Bovet P, et al. Association of car ownership and physical activity across the spectrum of human development: modeling the epidemiologic transition study (METS). BMC Public Health. 2015;15(1):173. PubMed ID: 25885263 doi:10.1186/s12889015-1435-9

31. Wolfe AM, Lee JA, Laurson KR. Socioeconomic status and physical fitness in youth: findings from the NHANES National Youth Fitness Survey. J Sports Sci. 2020;38(5):534-541. PubMed ID: 31952463 doi:10.1080/02640414.2020.1713688

32. Gerber M, Ayekoé SA, Beckmann J, et al. Effects of school-based physical activity and multi-micronutrient supplementation intervention on growth, health and wellbeing of schoolchildren in three African countries: the KaziAfya cluster randomised controlled trial protocol using a 2x2 factorial design. Trials. 2020;21(1):22. PubMed ID: 31907019 doi:10.1186/s13063-019-3883-5

33. Agherdien Y, George AC, Hendricks S. South End as We Knew it. Port Elizabeth: Western Research Group; 1997.

34. Southern Africa Development RaTI. One community many communities: a Nelson Mandela Bay Heritage and History Project (NMBHHP): forced removals in South End, North End, Salisbury PArk, Fairview, Willowdene and Korsten. 2013. http://sadratinstitute. org.za/project-programmes/one-community-many-communities/. Accessed March 3, 2021.

35. Hjelm L, Mathiassen A, Miller D, et al. VAM Guidance Paper. Creation of a Wealth Index. Rome, Italy: World Food Programme; 2017.
36. Filmer D, Pritchett LH. Estimating wealth effects without expenditure data or tears: an application to educational enrollments in states of India. Demography. 2001;38:115-32. PubMed ID: 11227840

37. Hills AP, Mokhtar N, Byrne NM. Assessment of physical activity and energy expenditure: an overview of objective measures. Front Nutr. 2014;1:5. PubMed ID: 25988109 doi:10.3389/fnut.2014.00005

38. Aadland E, Andersen LB, Skrede T, et al. Reproducibility of objectively measured physical activity and sedentary time over two seasons in children; comparing a day-by-day and a week-by-week approach. PLoS One. 2017;12(12):e0189304. PubMed ID: 29216318 doi:10. 1371/journal.pone.0189304

39. Troiano RP, Berrigan D, Dodd KW, et al. Physical activity in the United States measured by accelerometer. Med Sci Sports Exerc. 2008;40(1):181-188. PubMed ID: 18091006 doi:10.1249/mss. 0b013e31815a51b3

40. Clemente FM, Nikolaidis PT, Martins FM, et al. Physical activity patterns in university students: do they follow the public health guidelines? PLoS One. 2016;11(3):e0152516. PubMed ID: 27022993 doi:10.1371/journal.pone.0152516

41. Evenson KR, Catellier DJ, Gill K, et al. Calibration of two objective measures of physical activity for children. $J$ Sports Sci. 2008;26(14):1557-1565. PubMed ID: 18949660 doi:10.1080/ 02640410802334196

42. Inchley J, Currie D, Young T, et al. Growing up unequal: gender and socioeconomic differences in young people's health and well-being. In: Health Behaviour in School-Aged Children (HBSC) Study: International Report From the 2013/2014 Survey. Health Policy for Children and Adolescents. Geneva, Switzerland: World Health Organization; 2016:276.

43. Bull FC, Al-Ansari SS, Biddle S, et al. World Health Organization 2020 guidelines on physical activity and sedentary behaviour. $\mathrm{Br} J$ Sports Med. 2020;54(24):1451-1462. PubMed ID: 33239350 doi:10. 1136/bjsports-2020-102955

44. Kowalski KC, Crocker PRE, Faulkner RA. Validation of the physical activity questionnaire for older children. Pediatr Exerc Sci. 1997;9(2):174-186. doi:10.1123/pes.9.2.174

45. Léger LA, Mercier D, Gadoury C, et al. The multistage 20 meter shuttle run test for aerobic fitness. J Sports Sci. 1988;6(2):93-101. PubMed ID: 3184250 doi:10.1080/02640418808729800

46. Lang JJ, Wolfe Philips E, Orpana HM, et al. Field-based measurement of cardiorespiratory fitness to evaluate physical activity. Bull World Health Organ. 2018;96(11):794-796. PubMed ID: 30455535 doi:10. 2471/BLT.18.213728

47. Cohen J. Statistical Power Analysis for the Behavioral Sciences. Mahwah, NJ: Erlbaum; 1988.

48. West SG, Finch JF, Curran PJ. Structural equation models with nonnormal variables: problems and remedies. In: Hoyle RH, ed. Structural Equation Modeling Concepts, Issues, and Applications. Thousand Oakes: Sage; 1995:56-75.

49. McVeigh JA, Norris SA, de Wet T. The relationship between socioeconomic status and physical activity patterns in South African children. Acta Paediatr. 2004;93(7):982-988. PubMed ID: 15303817 doi:10.1111/j.1651-2227.2004.tb02699.x

50. Nyawose SE, Naidoo R. The impact of a school-based and family physical activity intervention on learners' health behaviour. African $J$ Phys Act Heal Sci. 2016;22:1.

51. Uys M, Broyles ST, Draper CE, et al. Perceived and objective neighborhood support for outside of school physical activity in South African children. BMC Public Health 2016;16(1):462. PubMed ID: 27246104 doi:10.1186/s12889-016-2860-0

52. McGrath LJ, Hopkins WG, Hinckson EA. Associations of objectively measured built-environment attributes with youth moderate-vigorous 
physical activity: a systematic review and meta-analysis. Sports Med. 2015;45(6):841-865. PubMed ID: 25618013 doi:10.1007/s40279015-0301-3

53. Sandercock G, Lobelo F, Correa-Bautista J, et al. The relationship between socioeconomic status, family income, and measure of muscular and cardiorespiratory fitness in Colombian schoolchildren. $J$ Pediatr. 2017;185:81-87.e2. PubMed ID: 28161198 doi:10.1016/j. jpeds.2016.12.058

54. Telama R, Yang X. Decline of physical activity from youth to young adulthood in Finland. Med Sci Sports Exerc. 2000;32(9):1617-1622. PubMed ID: 10994914 doi:10.1097/00005768-200009000-00015

55. Hills AP, King NA, Armstrong TP. The contribution of physical activity and sedentary behaviours to the growth and development of children and adolescents. implications for overweight and obesity. Sports Med. 2007;37(6):533-545. PubMed ID: 17503878 doi:10. 2165/00007256-200737060-00006

56. van Sluijs E, Ekelund U, Hansen BH, et al. Family car ownership and activity in young people: cross-sectional and longitudinal analyses using the International Children's Accelerometry Database. Lancet. 2018;392:S89. doi:10.1016/S0140-6736(18)32105-6

57. Craig E, Bland R, Reilly J. Objectively measured physical activity levels of children and adolescents in rural South Africa: high volume of physical activity at low intensity. Appl Physiol Nutr Metab. 2013; 38(1):81-84. PubMed ID: 23368832 doi:10.1139/apnm-2012-0115

58. Wong ML, Shiau S, Yin MY, et al. Decreased vigorous physical activity in school-aged children with human immunodeficiency virus in Johannesburg, South Africa. J Pediatr. 2016;172:103-109. PubMed ID: 26922104 doi:10.1016/j.jpeds.2016.01.034

59. McVeigh J, Meiring R. Physical activity and sedentary behavior in an ethnically diverse group of South African school children. $J$ Sport Sci Med. 2014;13:371-78.

60. Tomaz SA, Prioreschi A, Watson ED, et al. Body mass index, physical activity, sedentary behavior, sleep, and gross motor skill proficiency in preschool children from a low-to middle-income urban setting. J Phys Act Health. 2019;16(7):525-532. PubMed ID: 31154894 doi:10.1123/jpah.2018-0133

61. Abernathy TJ, Webster G, Vermeulen M. Relationship between poverty and health among adolescents. Adolescence. 2002;37:5567. PubMed ID: 12003291

62. Ruiz JR, Cavero-Redondo I, Ortega FB, et al. Cardiorespiratory fitness cut points to avoid cardiovascular disease risk in children and adolescents: what level of fitness should raise a red flag? A systematic review and meta-analysis. Br J Sports Med. 2016;50(23): 1451-1458. PubMed ID: 27670254 doi:10.1136/bjsports-2015095903

63. Ruiz JR, Castro-Pinero J, Artero EG, et al. Predictive validity of health-related fitness in youth: a systematic review. Br J Sports Med. 2009;43(12):909-923. PubMed ID: 19158130 doi:10.1136/bjsm. 2008.056499

64. Tomaz SA. Physical Activity and Gross Motor Skills in Rural South Africa. Cape Town, South Africa: University of Cape Town; 2018.

65. Cook CJ, Howard SJ, Scerif G, et al. Associations of physical activity and gross motor skills with executive function in preschool children from low-income South African settings. Dev Sci. 2019;22:e12820. PubMed ID: 30801916 doi:10.1111/desc. 12820

66. Walter CM. In-school physical activity patterns of primary school learners from disadvantaged schools in South Africa. Afr J Phys Health Educ Recreat Dance. 2011;17:780-789.

67. Pienaar AE, Visagie M, Leonard A. Proficiency at object control skills by nine- to ten-year-old children in South Africa: the NW-Child Study. Percept Mot Ski. 2015;121(1):309-332. doi:10.2466/10.PMS. $121 \mathrm{c} 15 \times 8$

68. Pienaar AE, Kemp C. Motor proficiency profile of grade 1 learners in the North West Province of South Africa: the NW-Child Study. S Afr J Res Sport Phys Educ Recreation. 2014;36:167-82.

69. Tomaz SA, Jones RA, Hinkley T, et al. Gross motor skills of South African preschool-aged children across different income settings. $J$ Sci Med Sport. 2019;22(6):689-694. PubMed ID: 30606626 doi:10. 1016/j.jsams.2018.12.009

70. Uys M, Bassett S, Draper CE, et al. Results from South Africa's 2016 report card on physical activity for children and youth. $J$ Phys Act Health. 2016;13:S265-S73. PubMed ID: 27848725 doi:10.1123/ jpah.2016-0409

71. Draper CE, Achmat M, Forbes J, et al. Impact of a community-based programme for motor development on gross motor skills and cognitive function in preschool children from disadvantaged settings. Early Child Dev Care. 2012;182(1):137-152. doi:10.1080/03004430. 2010.547250

72. Marshall SJ, Ramirez E. Reducing sedentary behavior: a new paragigm in physical activity promotion. Am J Lifestyle Med. 2011;5(6):518-530. doi:10.1177/1559827610395487

73. Atkin AJ, Corder K, Ekelund U, et al. Determinants of change in children's sedentary time. PLoS One. 2013;8(6):e67627. PubMed ID: 23840753 doi:10.1371/journal.pone.0067627

74. Arundell L, Fletcher E, Salmon J, et al. A systematic review of the prevalence of sedentary behavior during the after-school period among children aged 5-18 years. Int J Behav Nutr Phys Act. 2016;13(1):93. PubMed ID: 27549588 doi:10.1186/s12966-016-0419-1

75. Micklesfield LK, Pedro TM, Kahn K, et al. Physical activity and sedentary behavior among adolescents in rural South Africa: levels, patterns and correlates. BMC Public Health. 2014;14(1):40. doi:10. 1186/1471-2458-14-40

76. Koezuka N, Koo M, Allison KR, et al. The relationship between sedentary activities and physical inactivity among adolescents: results from the Canadian Community Health Survey. J Adolesc Health. 2006;39(4):515-522. PubMed ID: 16982386 doi:10.1016/j. jadohealth.2006.02.005

77. Kenney EL, Gortmaker SL. United States adolescents' television, computer, videogame, smartphone, and tablet use: associations with sugary drinks, sleep, physical activity, and obesity. $J$ Pediatrics. 2017;182:144-149. doi:10.1016/j.jpeds.2016.11.015

78. Gupta N, Mathiassen SE, Mateu-Figueras G, et al. A comparison of standard and compositional data analysis in studies addressing group differences in sedentary behavior and physical activity. Int J Behav Nutr Phys Act. 2018;15(1):53. PubMed ID: 29903009 doi:10.1186/ s12966-018-0685-1 